\title{
The criteria for evaluating shear stress measuring range and the lowest measurable shear stress of rotational viscometer
}

\author{
Qixue Qi ${ }^{\mathrm{a}, *}$, Yufen $\mathrm{Li}^{\mathrm{a}}$, Yun You ${ }^{\mathrm{b}}$ and Fulong Liao ${ }^{\mathrm{b}, *}$ \\ ${ }^{a}$ Hemorheology Laboratory, The First Affiliated Hospital, China Medical University, Shenyang, China \\ ${ }^{\mathrm{b}}$ Institute of Chinese Materia Medica, China Academy of Chinese Medial Sciences, Beijing, China
}

Received 7 January 2009

Accepted 15 January 2009

In the Guidelines for measurement of blood viscosity and erythrocyte deformability by ICSH in 1986, it points out that the viscometer for hemorheology should ideally be able to operate over a wide range of shear conditions, and for a constant shear-rate viscometer a high-shear measurement at 200/second and a low-shear measurement at $1 /$ second (or shear-rates approximating to these values if they are not attainable in the instrument used) should be made [1]. It also states that a high degree of instrument sensitivity is required for measuring viscosity at low shear. A suitable shear stress measuring range and a high degree sensitivity at low shear-rate are required for measuring blood viscosity. Unfortunately, many of the industrial viscometers do not meet the requirements [2]. In fact, the lowest measurable shear-stress is a critical parameter for a rotational blood viscometer. However, the criteria for evaluating shear measuring range and the lowest measurable shear-stress are not clearly described in the guidelines. We proposed double 5\% criteria for the evaluation, i.e. less than 5\% error in viscometry and less than 5\% in coefficient of variation as "measurable" criteria. Recently, we experienced the criteria with a domestic rotational viscometer (anonym for avoiding possible conflicts in commercial interests).

The viscometer is a shear-rate controlled rotational viscometer with double gap cylinder sensor designed for measuring blood and plasma viscosities. A suspending torsion strip is employed as the shearstress sensing element. The viscometer works in the shear-rate range of 1-220/second and shear-stress range of 10-2000 $\mathrm{mPa}$ according to the specifications described in the user's manual. The sensor temperature is controlled at fixed $37 \pm 0.5^{\circ} \mathrm{C}$. The required sample volume is $1.2 \mathrm{ml}$.

We selected a number of standard oils (provided by the Chinese Academy of Metrology), including GBW(E)130251, GBW(E)130253, GBW(E)130254 and GBW(E)130255, for evaluation of the viscome-

\footnotetext{
${ }^{*}$ Corresponding authors: Qixue Qi, Hemorheology Laboratory, The First Affiliated Hospital, China Medical University, Shenyang 110001, China. E-mail: qqx5312@ sohu.com.

Fulong Liao, Institute of Chinese Materia Medica, China Academy of Chinese Medial Sciences, Beijing 100700, China. E-mail: liaofulong100@yahoo.cn.
} 
ter. The viscosities of the oils are $1.346,4.860,9.006$ and $20.38 \mathrm{mPa} \cdot \mathrm{s}$ at $37^{\circ} \mathrm{C}$, respectively, with relative uncertainty less than $0.6 \%$. Distilled water was also employed as a low viscosity Newtonian fluid. Its viscosity is $0.692 \mathrm{mPa} \cdot \mathrm{s}$ at $37^{\circ} \mathrm{C}$.

The standard oils were measured one by one by the viscometer at programmed down-hill shear-rates of 200,180,10, 5, 3 and 1/second. At each shear-rate, eighty shear-stress readings were computerized obtained and averaged to get a mean stress for automatic calculating the viscosity value. For avoiding influences come from other factors, such as temperature error in re-balancing and volume error in sampling, the oil sample was kept in the sensor during repeated six tests. The relative error in viscometry and the measuring coefficient of variation $(\mathrm{CV})$ were calculated for the six repeated tests for each standard oil. When a criterion of the double $5 \%$ criteria was unfulfilled or both of them were unfulfilled, the corresponding shear-stress was considered "unmeasured".

The evaluation results are summarized in Table 1. Generally speaking, the error in viscometry and the coefficient of variation are small for the high viscosity Newtonian fluids, such as GBW(E)130254 (9.006 mPa.s) and GBW(E)130255 (20.38 mPa.s). The CVs for GBW(E)130255 are all within 1\%, and

Table 1

The relative error in viscosity and the measuring coefficient of variation are evaluated for each standard Newtonian fluid by six repeated tests

\begin{tabular}{|c|c|c|c|c|c|c|}
\hline \multirow[t]{2}{*}{ Sample } & \multicolumn{6}{|c|}{ Shear-rate $(1 / s)$} \\
\hline & 1.0 & 3.0 & 5.0 & 10.0 & 180 & 200 \\
\hline \multicolumn{7}{|l|}{ Water } \\
\hline Mean $(\mathrm{mPa} \cdot \mathrm{s})$ & 1.67 & 0.80 & 0.59 & 0.71 & 0.67 & 0.69 \\
\hline $\mathrm{SD}(\mathrm{mPa} \cdot \mathrm{s})$ & 0.72 & 0.26 & 0.16 & 0.09 & 0.01 & 0.01 \\
\hline $\mathrm{CV}(\%)$ & 43.1 & 32.5 & 27.1 & 12.5 & 2.64 & 2.73 \\
\hline Error $(\%)$ & 141 & 15.6 & -14.7 & 2.60 & -3.18 & -0.29 \\
\hline \multicolumn{7}{|l|}{ GBW(E)130251 } \\
\hline Mean $(\mathrm{mPa} \cdot \mathrm{s})$ & 1.49 & 1.50 & 1.51 & 1.33 & 1.37 & 1.37 \\
\hline $\mathrm{SD}(\mathrm{mPa} \cdot \mathrm{s})$ & 0.12 & 0.03 & 0.12 & 0.02 & 0.02 & 0.02 \\
\hline $\mathrm{CV}(\%)$ & 8.05 & 2.00 & 7.95 & 1.50 & 1.46 & 1.46 \\
\hline Error $(\%)$ & 10.7 & 11.4 & 12.2 & -1.19 & 1.78 & 1.78 \\
\hline \multicolumn{7}{|l|}{ GBW(E)130253 } \\
\hline Mean $(\mathrm{mPa} \cdot \mathrm{s})$ & 4.54 & 4.62 & 4.68 & 4.89 & 5.09 & 5.05 \\
\hline $\mathrm{SD}(\mathrm{mPa} \cdot \mathrm{s})$ & 0.10 & 0.12 & 0.12 & 0.14 & 0.13 & 0.14 \\
\hline CV (\%) & 2.20 & 2.60 & 2.56 & 2.86 & 2.55 & 2.77 \\
\hline Error $(\%)$ & -6.58 & -4.94 & -3.70 & 0.62 & 4.73 & 3.91 \\
\hline \multicolumn{7}{|l|}{ GBW(E)130254 } \\
\hline Mean $(\mathrm{mPa} \cdot \mathrm{s})$ & 9.03 & 8.59 & 8.78 & 8.98 & 8.94 & 8.90 \\
\hline $\mathrm{SD}(\mathrm{mPa} \cdot \mathrm{s})$ & 0.10 & 0.06 & 0.13 & 0.18 & 0.09 & 0.09 \\
\hline $\mathrm{CV}(\%)$ & 1.11 & 0.70 & 1.48 & 2.00 & 1.01 & 1.01 \\
\hline Error (\%) & 0.27 & -4.62 & -2.51 & -0.29 & -0.73 & 1.18 \\
\hline \multicolumn{7}{|l|}{ GBW(E)130255 } \\
\hline Mean $(\mathrm{mPa} \cdot \mathrm{s})$ & 19.69 & 20.44 & 20.76 & 20.75 & 20.70 & 20.16 \\
\hline $\mathrm{SD}(\mathrm{mPa} \cdot \mathrm{s})$ & 0.13 & 0.15 & 0.09 & 0.06 & 0.07 & 0.16 \\
\hline $\mathrm{CV}(\%)$ & 0.66 & 0.73 & 0.43 & 0.28 & 0.34 & 0.79 \\
\hline Error $(\%)$ & -3.39 & 0.29 & 1.86 & 1.82 & 1.57 & -1.08 \\
\hline
\end{tabular}

Note: The figures of $\mathrm{CV}$ and error in bold and italics are those bigger than 5\%, indicating a situation of "unmeasured" shear stress encountered. 
those for GBW(E)130254 are within 2\%. The error in viscosity measurement was mostly within 3\%, except two of them between 3-5\%. The corresponding shear-stress at the high shear-rate of 200/second for GBW(E) 130255 reaches $4076 \mathrm{mPa}$. Therefore, we can estimate that the maximum measurable shear-stress should beyond $4000 \mathrm{mPa}$. According to the measurement at 1/second for GBW(E)130254, $9.01 \mathrm{mPa}$ is still measurable.

The low viscosity Newtonian fluids, GBW(E)130253 (4.860 mPa.s), GBW(E)130251 (1.346 mPa.s) and water $(0.692 \mathrm{mPa} \cdot \mathrm{s})$, contribute to the determination of lowest measurable shear stress. We mark the "unmeasured" data in bold and italics in Table 1, indicating one criterion unfulfilled or both of them unfulfilled. The data show that unmeasured shear-stress is $6.92 \mathrm{mPa}$ for water, $6.73 \mathrm{mPa}$ for GBW(E)130251 and $4.86 \mathrm{mPa}$ for GBW(E)130253. As mentioned in the previous paragraph, $9.01 \mathrm{mPa}$ is measurable. So, the lowest measurable shear-stress should be a value between $6.92-9.01 \mathrm{mPa}$ (7-9 $\mathrm{mPa}$ roughly). The evaluated measurable shear-stress is agreeable with the description in the specification.

Based on the experience of the evaluation, we believe that the double $5 \%$ criteria for evaluating shearstress measuring range and the lowest measurable shear-stress of a rotational viscometer are meaningful and practical. By employing a number of standard Newtonian fluids, the criteria can be easily carried out for viscometer evaluation.

\section{Acknowledgement}

This work was supported by NSFC projects (10672192, 30801530).

\section{References}

[1] ICSH, Guidelines for measurement of blood viscosity and erythrocyte deformability, Clin. Hemorheol. 6(1986), 439-453.

[2] O.K. Baskurt, M.R. Hardeman, M.W. Rampling and H.J. Meiselman (eds), Handbook of Hemorheology and Hemodynamics, IOS Press, Amsterdam, 2007, pp. 246-247. 